\title{
ROOSTING HABITS OF AN URBAN MERLIN
}

E. OTTO HOHN, 11511 - 78 Avenue, Edmonton, Alberta. T6G ON4

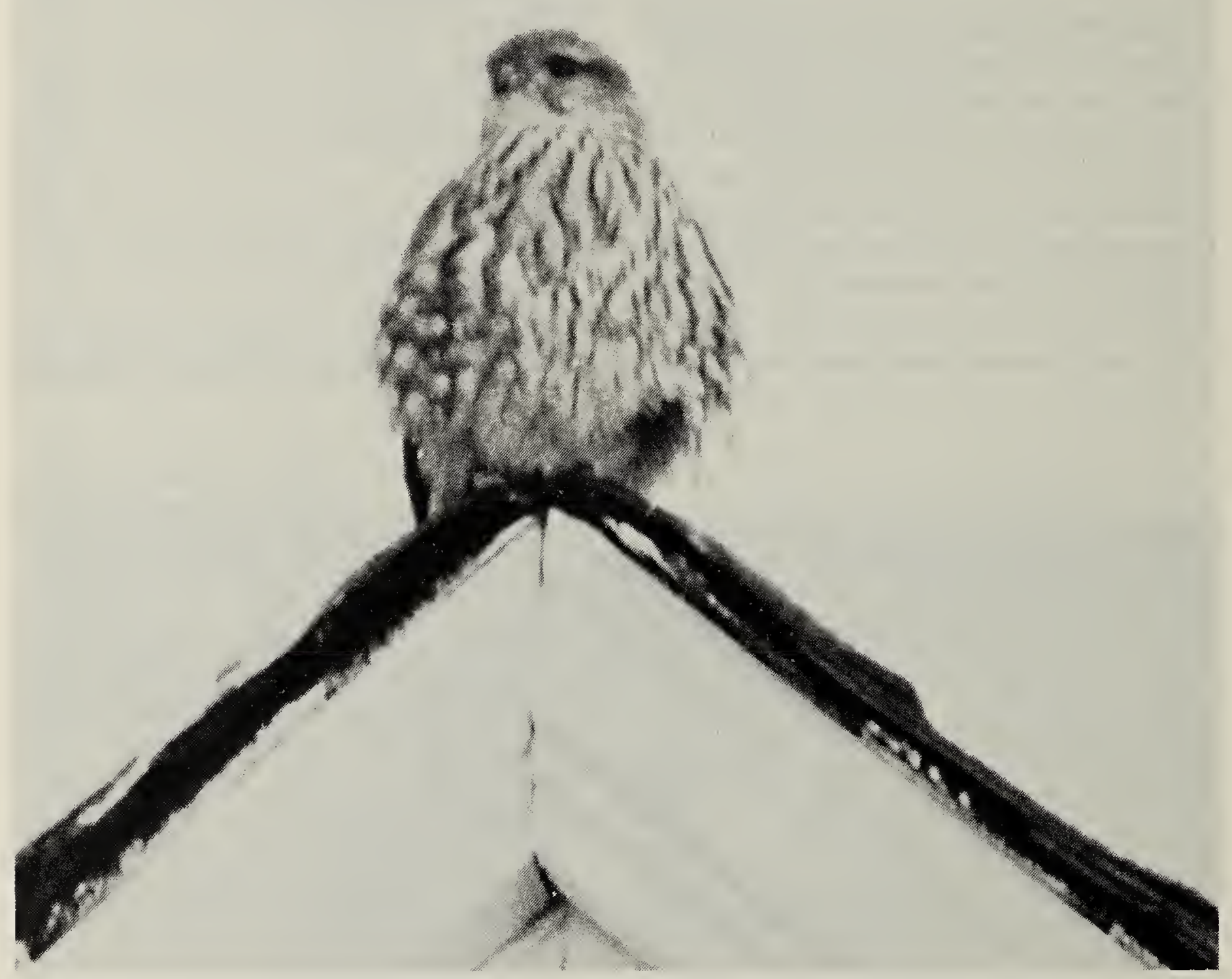

The Merlin on one of its favourite pre-roosting perches on a house roof on the opposite side of the small porch from the roost

At dusk on 17 December 1985 I saw a Merlin resting on a lamp post by a small park in a residential part of Edmonton, not far from the wooded slopes of the North Saskatchewan River valley. I surmised that the hawk was about to roost in one of a group of spruces in the park. Later observations showed that it did indeed come to this area to roost, but the actual roosting place was in a spruce standing beside the front door of one of the houses facing the park. This tree had two trunks close together, apparently growing from the same root. This factor and the nearness of the two story house probably made this tree a more sheltered environment than 
a freestanding single-trunk spruce and may have influenced the Merlin's choice.

An adult male Merlin, presumably the same bird was observed in the immediate area of this roost on 57 occasions between 17 December 1985 and 15 May 1986.

On these occasions when I was on the scene before the hawk's arrival it nearly always came in from the direction of the river valley.

It would then stay on one of seven different perches, of which only two were used frequently, for an appreciable period before flying into the roosting tree. Waiting time on the perch on 19 evenings between 4 February and 11 May ranged from 8 to 34 minutes, with an average of 17.4 minutes. Almost always the hawk perched in such a way as to face the brightest segment of the sky.

The hawk never arrived at a perch in the roosting area with prey. Most of the time it remained immobile on the perch. Preening movements took up only a very small fraction of the time spent perched and were totally absent on some evenings. The bird's behavior gave the impression that it required a period of quiet rest before the urge to enter the roost reached threshold level.

When leaving the perch, the hawk, without any preliminary flying intention movements, would first fly downward and then swing upward so as to enter the tree at about mid-height. For a number of consecutive observations it would use the same perch then switch for at least several days to another, perhaps after some time returning to using the first one.

Times of arrival on the perch and of entering the roost in relation to sunset changed sharply at the end of February. Before this period the falcon generally arrived 20 to 30 minutes before sunset and flew into the roost about sunset. In March,

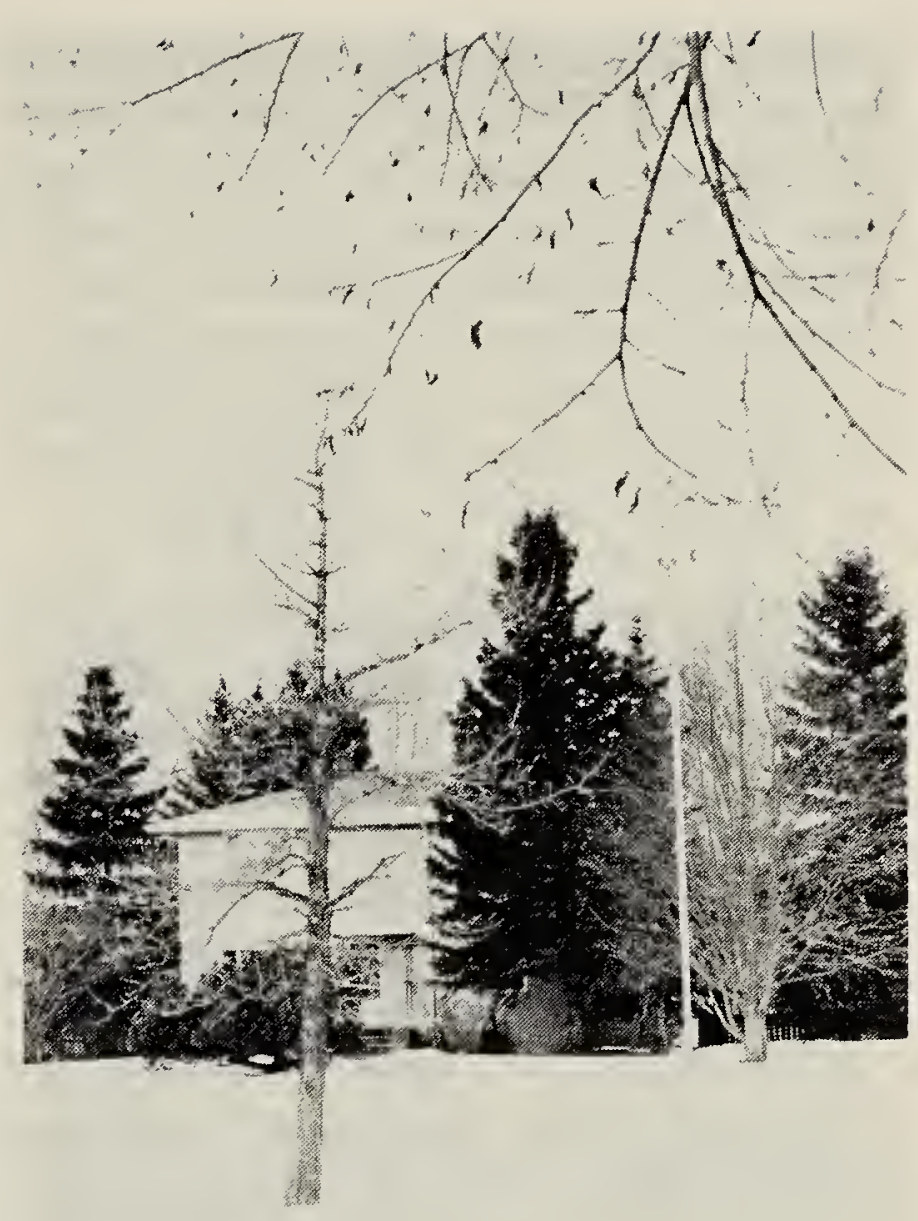

The small oak in the left foreground was another much used perch from which the hawk would (in due course) swoop into the roost in the spruce immediately right of the house

April and May it did not arrive in the roosting area until sunset or even later and it would fly into the roosting tree some 20 minutes later. During this time visibility was on occasion so poor that the falcon could be seen to leave its perch but would immediately be lost to view.

The change in roosting time as spring advanced may have been due to the hawk's becoming involved in breeding. The fact that it did not use the roost under observation after mid-May may suggest that it roosted near its (presumed) nest when the demands of its young for food became heavy. 
The evident relationship between sunset and arrival in the roosting area and entry into the roost, suggest that both may have been determined by light intensity. However, I did not find that these events always took place earlier on overcast than on sunny evenings. I therefore conclude that light intensity plays an important but not exclusive role in their timing.

Cramp and Simmonds, who give an account of roosting in Merlins, state that before settling down for the night the birds often engage in spectacular aerial chases. These are more frequently seen near roosts used by more than one bird. ${ }^{1}$ I only saw two aerial chases.

On 19 January, two Merlins, engaged in an aerial chase, were seen 17 minutes before sunset.

Almost as soon as they came into view they were joined by a third falcon. The usual kee kee kee call was heard from at least one of the group, which was lost to view after a few seconds. At that time the hawk had not as yet arrived near the roost. Eighteen minutes before sunset on 2 February, as I was walking from home to the roost, a Merlin chasing another flew overhead. Nearer the roost a female Merlin was perched on a weeping birch in a garden. It kept up a series of calls throughout the time I was within earshot. About 2 minutes later, I arrived in the roosting area and the male Merlin was already on one of its "traditional" perches. It flew into the roosting tree 6 minutes after sunset.

' CRAMP,S. and SIMMONDS, K.E.L. 1980. Handbook of the birds of Europe, the Middle East and North Africa. Vol. 2. Oxford. 695 pp.

\section{AN UNUSUAL VISITOR}

CURTIS POLLOCK, Box 40, Hyas, Saskatchewan. SOA OLO

When Randy Krukoff of Canora arrived home around midnight on 8 March, he found an unusual visitor waiting by the door, this Eastern Screech-Owl. Although locally common in eastern Canada and the United States, it is considered quite rare in Saskatchewan where it is at the extreme northwest portion of its range. In The Birds of Canada (Godfrey, 1966; Nat. Mus. Canada, Ottawa) it is described as a"permanent resident in ... southern Saskatchewan (Yorkton; breeding range not well known, but the bird has been reported occurring west to Cypress Hills region and north to Saskatoon)." The Birds of North America states that "Eastern Screech-owls are common in a wide variety of habitats: woodlots, forests, swamps, orchards, parks, suburban gardens" (Robbins, et. al., 1983; Western Publ. Co., N.Y.). However, the Saskatchewan Natural History Society says that they prefer wooded river valleys, and society members conducted a search last April for evidence of the bird breeding in the Assiniboine and Whitesand River valleys in this area which is considered to be one of the most probable locales for the species' occurrence in this province. They were unsuccessful at that time.

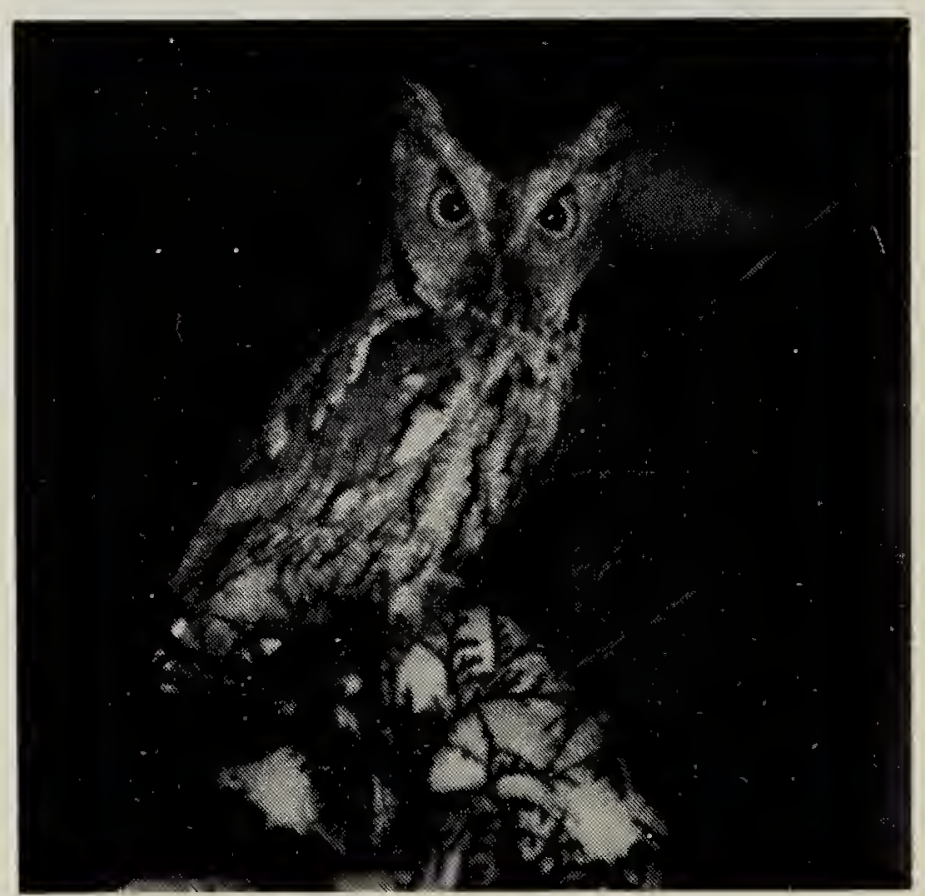

